\title{
Functional decline in geriatric rehabilitation ward; is it ascribable to hospital acquired infection? A prospective cohort study
}

Marie Laurent ${ }^{1,2^{*}}$ (D), Nadia Oubaya ${ }^{1,3}$, Jean-Philippe David ${ }^{1,4}$, Cynthia Engels ${ }^{1,5}$, Florence Canoui-Poitrine ${ }^{1,3}$, Lola Corsin ${ }^{2}$, Eveline Liuu ${ }^{6}$, Etienne Audureau ${ }^{1,3}$, Sylvie Bastuji-Garin ${ }^{1,3+}$ and Elena Paillaud ${ }^{1,7 \dagger}$

\begin{abstract}
Background: In some European countries, including France, older patients with functional decline in acute units are transferred to geriatric rehabilitation units. Some patients may not benefit from their stay in a geriatric rehabilitation unit and paradoxically worsened their functional status. Previous prognostic models of functional decline are based on only baseline parameters. However, some events can occur during rehabilitation and modify the association between baseline parameters and rehabilitation performance such as heart failure episode, falls or hospital-acquired infection (HAl). The incidence of functional decline in these units and factors associated with this decline have not been clearly identified.

Methods: We used a prospective cohort of consecutive patients aged $\geq 75$ years admitted to a geriatric rehabilitation unit in a French university hospital. The main endpoint was functional decline defined by at least an one-point decrease in Activities of Daily Living (ADL) score during the stay. Baseline social and geriatric characteristics were recorded and comorbidities were sought by the Cumulative Illness Rating Scale for Geriatrics (CIRS-G). During follow-up, hospital-acquired infection (HAI) was recorded, as was ADL score at discharge. Multivariate logistic regression and mediation analyses were used to identify factors associated with ADL decrease. (Continued on next page)
\end{abstract}

\footnotetext{
* Correspondence: marie.laurent@aphp.fr

†Sylvie Bastuji-Garin and Elena Paillaud contributed equally to this work. 'Univ Paris Est Creteil, INSERM, IMRB, CEpiA Team, F-94010 Creteil, France ${ }^{2} \mathrm{AP}-\mathrm{HP}$, Hopital Henri Mondor, Departement de médecine interne et gériatrie, F-94010 Creteil, France

Full list of author information is available at the end of the article
}

(c) The Author(s). 2020 Open Access This article is licensed under a Creative Commons Attribution 4.0 International License, which permits use, sharing, adaptation, distribution and reproduction in any medium or format, as long as you give appropriate credit to the original author(s) and the source, provide a link to the Creative Commons licence, and indicate if changes were made. The images or other third party material in this article are included in the article's Creative Commons licence, unless indicated otherwise in a credit line to the material. If material is not included in the article's Creative Commons licence and your intended use is not permitted by statutory regulation or exceeds the permitted use, you will need to obtain permission directly from the copyright holder. To view a copy of this licence, visit http://creativecommons.org/licenses/by/4.0/ The Creative Commons Public Domain Dedication waiver (http://creativecommons.org/publicdomain/zero/1.0/) applies to the data made available in this article, unless otherwise stated in a credit line to the data. 
(Continued from previous page)

Results: Among the 252 eligible patients, 160 (median age 84 years [interquartile range (IQR) 80-88] had available ADL scores at baseline (median score 7 [IQR 4-10]) and at discharge (median 9 [6-12]). Median CIRS-G score was 11 [8-13], 23 (14\%) had a pulmonary HAl; 28 (17.5\%) showed functional decline. On multivariable analysis, functional decline was associated with comorbidities (global CIRS-G score, $P=0.02$, CIRS-G for respiratory disease [CIRS-G-R] $\geq 2, P=0.02$, or psychiatric disease, $P=0.02)$ and albumin level $<35 \mathrm{~g} / \mathrm{l}(p=0.03)$. Significant associations were found between functional decline and CIRS-G-R (OR 3.07 [95\%CI 1.27-7.41], $p=0.01)$, between functional decline and pulmonary HAI (OR 3.12 [1.17-8.32], $p=0.02)$, and between CIRS-G-R and pulmonary HAI (OR 12.9[4.4-37.7], $p=$ $0.0001)$. Theses associations and the reduced effect of CIRS-G-R on functional decline after adjusting for pulmonary HAI (OR 2.26 [0.83-6.16], $p=0.11$ ) suggested partial mediation of pulmonary HAl in the relation between CIRS-G-R and functional decline.

Conclusion: Baseline comorbidities were independently associated with functional decline in patients hospitalized in a geriatric rehabilitation unit. Pulmonary HAI may have mediated this association. We need to better identify patients at risk of functional decline before transfer to a rehabilitation unit and to test the implementation of modern and individual programs of rehabilitation outside the hospital for these patients.

Keywords: Comorbidity, Hospitals, Rehabilitation, Elderly, Acquired hospital infection functional decline

\section{Background}

Hospital admissions are important causes of functional decline among older patients [1]. The decline has important effects on quality of life and is associated with increased risk of longer hospital stay, death, nursing home transfer, and rehospitalization [2-4]. Older age, preexisting altered functional status, cognitive impairment, low mobility during the stay and length of stay have been reported to increase the risk of functional decline in acute unit [5-12]. Functional decline can lead to a restriction of participation in meaningful daily activities, which can be dramatic, as studies have shown that the main criteria for frail older adults to express satisfaction with their life is to be able to continue everydays' occupations and way of living, opposed to using homecare services, first reason given for unsatisfaction [13]. For older adults with cancer for example, studies have shown that autonomy was even more valued than healing or lifespan [14]. Functional Independence Measure (FMI), Barthel's score and Katz's Acitiviy of Daily Living score (ADL) have been recognized to have good metrics proprieties and are widely used to assess functional decline. All are multidisciplinary, simple and quick to use. However, some studies suggest that for frail older adults Katz ADL is more appropriate [15]. It is also the tool recommended for best practices in nursing care to older adults [16].

In some European countries, including France, older patients with functional decline in acute units are transferred to geriatric rehabilitation units [1, 17-19] that are inpatient units specialized in the multidisciplinary rehabilitation of older frail patients with chronic diseases and geriatric syndromes [20]. A meta-analysis showed that these units may improve functional status and may limit nursing-home transfer and mortality [21]. One study suggested that some patients may not benefit from their stay in a geriatric rehabilitation unit and paradoxically worsened their functional status [22]. The incidence of functional decline in these geriatric rehabilitation units and factors associated with this decline have not been clearly identified [16]. Previous studies in rehabilitation units focused on specific groups of patients, such as those with hip fracture [22-27] or cognitive impairment $[7,22]$. Generalization of results from these studies to the heterogenous population of geriatric rehabilitation units is limited. As compared with younger patients, older patients admitted to a geriatric rehabilitation unit had multiple comorbidities in addition to the primary diagnosis that triggered their admission to the rehabilitation unit $[26,28]$.

Results concerning comorbidities as predictors of functional outcome for older frail patients are discordant [5, 25-33]. Mechanisms that could tie baseline comorbidities to rehabilitation performance remain unclear [25, 26, 28-32]. Moreover, previous prognostic models are based on only baseline parameters. However, some events can occur during rehabilitation and modify the association between baseline parameters and rehabilitation performance such as heart failure episode, falls or hospital-acquired infection (HAI) which could modify the relationship between the comorbidities and functional decline [34]. Few studies have assessed the link between HAI and functional decline and most of them were performed in acute medical wards. Yet, the incidence of HAI in rehabilitation units is higher than in acute wards [35]. HAIs remain a major cause of morbidity and mortality despite advances in antimicrobial therapy, better supportive care modalities, and the use of a wide range of preventive measures [35]. 
The first aim of this study was to assess the incidence of functional decline in older patients during a stay in a rehabilitation unit. The secondary aim was to assess association between the functional decline during a stay in a rehabilitation unit and baseline exposition variables such as comorbidities or nutritional status and exposition variables during follow up such as HAI.

\section{Methods}

Our manuscript adhere to the appropriate STROBE guidelines.

\section{Study design and patients}

We used data from a previously described prospective cohort study conducted between July 2006 and November 2008 in a teaching hospital (1300 beds) in the Paris area, France [36]. The cohort comprised 252 consecutive patients aged 75 years or older who were referred to a geriatric rehabilitation unit from acute medical or surgical units during the study period. This rehabilitation unit focuses on minimizing dependency and enabling return to home and participation in community activities of patients with functional impairments that are expected to improve.

In addition to medical care provided by geriatricians and standard nursing care, inpatient rehabilitation typically included both physical therapy ( $1 \mathrm{~h} /$ day $)$ and occupational therapy $(1 \mathrm{~h} /$ day $)$ on 5 of 7 days per week. Inclusion criteria were medically stable status at admission, need for long-term care and rehabilitation, and absence of terminal disease (severe dementia with MiniMental State Examination (MMSE) less than 10 associated with reserved prognosis based on geriatric evaluation), fever, infection, active known malignant process, or known immunological dysfunction. All patients underwent routine assessment by multi-disciplinary staff including physicians, nurses, a physical therapist, an occupational therapist and a social worker. Patients were followed up until death if death occurred during their rehabilitation unit, discharge from the rehabilitation unit if discharge occurred before 3 months after inclusion. If discharge from the rehabilitation unit occurred after 3 months, data of follow up were recorded at 3 months. The study complied with the Declaration of Helsinki and was approved by the Paris XII ethics committee (no. SCR06010), Paris, France. Written informed consent was obtained from each patient before study inclusion.

\section{Data collection of exposure variables Exposure variables at baseline}

Baseline data were collected for each patient, using a standardized form before admission to the geriatric rehabilitation unit: sociodemographic information (age, sex, living conditions) and main acute diagnosis.
Comorbidities were evaluated using the Cumulative Illness Rating Scale for Geriatrics (CIRS-G) [37], which scores diseases in 14 organ systems on a $0-4$ grading scale of severity (a higher score indicates higher comorbidity). Paper and computerized medical records collected during acute hospitalization were used to define CIRS-G for each patient. The comorbidity index (CIRS$G$ Index) was calculated as the number of domains with score $\geq 2$ and ranged from 0 to 14 . The 14 domains were also assessed separately and were considered altered with CIRS-G score $\geq 2$. Cognitive function was assessed by the Mini-Mental State Examination (MMSE, score < 24 considered abnormal) [38] and renal function by the Cockroft creatinine clearance $(\mathrm{ml} / \mathrm{min})$ [39]. Serum albumin level $<35 \mathrm{~g} / \mathrm{L}$ was considered low [40].

\section{Exposure variables during follow up}

During follow-up, 2 of the co-authors (ML and EL) visited each patient once a week and reviewed the medical records with the attending physician and nurses to assess HAI in the rehabilitation unit. HAIs were diagnosed by consensus between 2 investigators (M.L. and E.L.). New onset of HAI was defined as a HAI that was not present at admission and was diagnosed after day 3 of admission in the rehabilitation unit and that met the Centers for Disease Control and Prevention definition of nosocomial infection [41]. Among bacterial infections, only those treated with antibiotics were taken into account; asymptomatic urinary tract infections were not included. When patients experienced more than one HAI, only the first episode was considered in the statistical analysis.

\section{Outcome}

Functional status was assessed by trained rehabilitation unit staff by the ADL scale, with scores ranging from 0 to 12,12 indicating no impairment in all 6 activities, (bathing, dressing, toilet use, continence, transfer and feeding). For each activity, the score could be 0 (unable to perform the activity without complete help), 1 (able to perform the activity with little assistance), and 2 (able to perform the activity without any help) [42]. ADL was also assessed at discharge from the rehabilitation unit.

The outcome was functional decline during the rehabilitation unit stay defined by at least a one-point decrease in ADL score using difference between ADL assessed at admission and at discharge from the rehabilitation unit. If discharge from the rehabilitation unit occurred after 3 months, functional decline was recorded at 3 months. We have included all patients admitted to rehabilitation unit independently of their ADL level at baseline (equal or less than 12) to reflect the real life in a rehabilitation unit. Only patients with an ADL level equal to zero at baseline were not included in analysis of 
factors associated with functional decline because their functional status cannot decrease more.

\section{Statistical analysis}

Categorical variables are described as numbers (\%) and were compared by chi-square test or Fisher exact test, as appropriate. Continuous variables are described as median (interquartile range $[\mathrm{IQR}]$ ) and were compared by the nonparametric Mann-Whitney test. Characteristics of patients with unavailable ADL data at discharge were compared to those with available data. Considering this latter group, we then compared the groups with and without functional decline in terms of baseline characteristics. In univariate analysis, associations were assessed using logistic regression model and crude odds ratios (ORs) were estimated with their 95\% confidence intervals (95\% CIs). Bivariate analyses were performed to identify the potential confounding factors. The assumption of loglinearity for continuous variables was checked using likelihood ratio tests comparing models with the variable handled in continuous versus in categorical way. We used the same methodology to test interactions. We looked for relevant interactions based on the literature: we tested interaction between main acute diagnosis and baseline ADL, between Pulmonary HAI and CIRS-G for respiratory disease, between Acquired Pulmonary Infection and CIRS-G Index and between MMSE. Variables associated with functional decline on univariate analysis at $P<0.15$ were then entered into a multivariate logistic regression model. The model was built using manual stepwise approach, (manual backward and forward approaches). To avoid introducing strongly correlated variables into multivariate models, we assessed correlations by using Cramer's $\mathrm{V}$ for categorical variables and the nonparametric Spearman's rank correlation coefficient (Rho) for quantitative variables using a correlation matrix. All models including albumin level were systematically adjusted for C-reactive protein (CRP) level, as appropriate [40]. Calibration of the final model was assessed using Hosmer-Lemeshow test. Finally, and in accordance with our hypothesis, we examined whether HAI occurrence potentially mediated the relation between comorbidities and functional decline, as illustrated in the conceptual framework shown in Fig. 1. According to Baron and Kenny [43], evidence for a partial mediating effect was assessed by the statistical significance [43-46] of the following associations:

1) between comorbidities as the independent exposure of the interest $(\mathrm{A})$ and functional decline as the outcome $(\mathrm{Y})$,

2) between comorbidities and HAI as the mediating factor $(M)$,

3) and between HAI and functional decline and by a reduced effect of comorbidities on functional decline after adjusting for HAI.

\section{Sensitivity analyses}

To test the robustness of our results, we performed three sensitivity analyses on the final models. Using the hypothesis of maximal bias, we first considered that all patients with missing discharged ADL data had functional decline, and second that these patients had no functional decline. Finally, we used a multiple imputation approach with the multiple-multivariate imputation-by-chained-equations procedure with the missing-at-random assumption. We used all baseline covariates and outcomes together to impute missing data values and independently analyzed 20 copies of the data.

All tests were two-tailed. $P \leq 0.05$ was considered statistically significant. Data were analyzed by using STATA v11.0 (StataCorp, College Station, TX, USA).

\section{Results}

The 15 patients who died during their stay in the rehabilitation unit were not included in the present study. Among the remaining 237 patients, 72 (30.3\%) had missing ADL data at discharge (Fig. 2). These patients were older, had lower admission ADL values, a higher number of comorbidities and a higher rate of HAI during rehabilitation stay than the 165 patients with available data (all $p<0.05$ ) (supplemental data - Appendix 1).

Among the 165 patients with available ADL data at discharge, 5 patients had an ADL score equal to 0 at

(M)

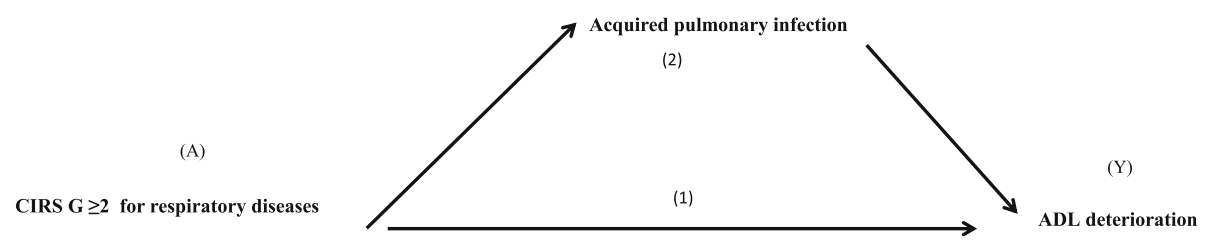

Fig. 1 Conceptual framework of the causal structure modelizing mediation. (1) Direct effect of CIRS-G $\geq 2$ for respiratory diseases (CIRS-G-R) on activities of daily living (ADL); and (2) indirect effect via acquired pulmonary infection. Legends (A) exposure of interest, (M) mediating factor, (Y) outcome 


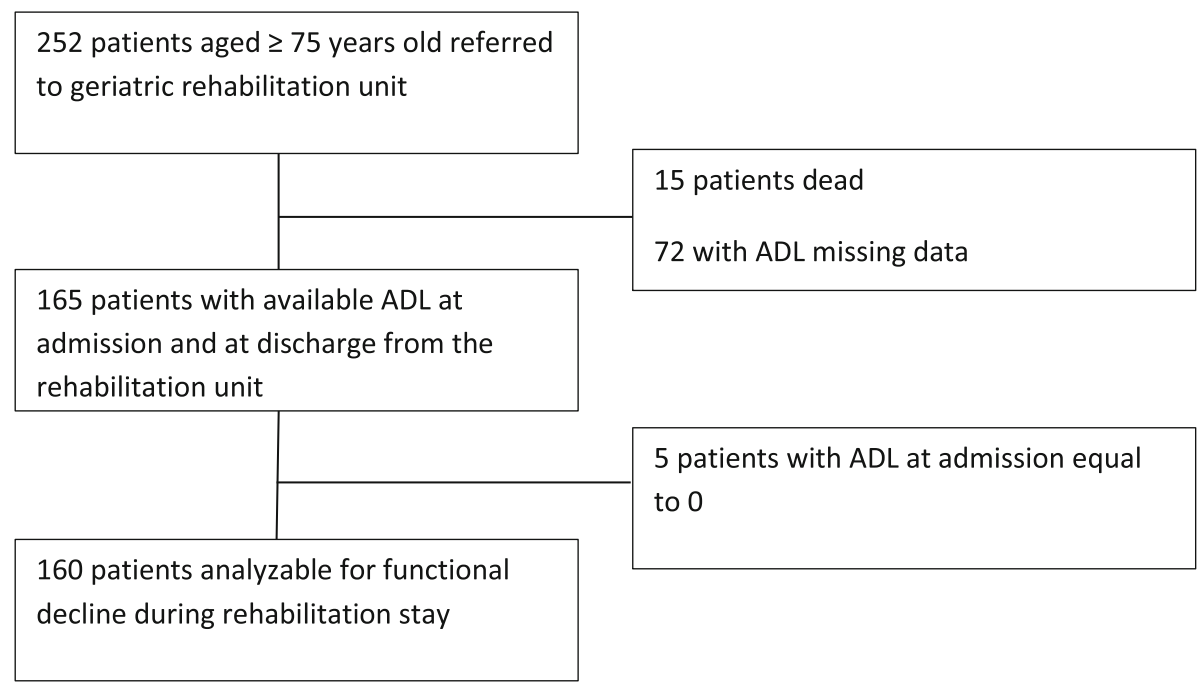

Fig. 2 Flow chart of the study. Functional decline was defined by at least a one-point decrease in ADL score using difference between ADL assessed at admission and at discharge from the rehabilitation unit

baseline, they were excluded from the analysis of factors associated with functional decline due to the inability to detect ADL deterioration in these patients. In patients analyzed for factors associated with functional decline, at baseline 17 patients had an ADL score equal to 12 and 143 patients had an ADL score of less than 12. Median ADL at discharge from the rehabilitation unit was significantly lower for patients with than without functional decline $(4.5[1-9]$ vs $10[6-12] p<0.0001)$. In study population, incidence of functional decline between admission in rehabilitation unit and discharge from rehabilitation unit was $17.5 \%$. Forty-Eight (30\%) had a HAI (Table 1), $42.9 \%$ in functional decline group and $27.3 \%$ in group without functional decline ( $p=0.11), 120$ (75\%) patients had CIRS-G score $\geq 2$ for psychiatric diseases (89.3\% in functional decline group and $72 \%$ in group without functional decline, $p=0.06$ ) and $93 / 120$ patients with CIRS-G score $\geq 2$ for psychiatric diseases had MMS $<25$. Median length of unit stay was 29 days [1563], with no difference between the groups with and without functional decline (median 35.5 days [14.5-79] vs 29 days [15-60], $P=0.80$ ). Twenty-eight patients had stayed longer than 3 months, maximum length of stay was 221 days. All other variables that were compared between the groups with and without functional decline are presented in Table 1. On univariate analysis, global CIRS-G and CIRS-G Index were significantly higher for patients with than without functional decline. Among the CIRS-G categories, respiratory and psychiatric diseases were significantly more prevalent in patients with functional decline. These patients had also lower MMSE values and low albumin level. The occurrence of pulmonary HAI was significantly associated with functional decline (OR 3.12 [1.17-8.32], $p=0.02$ ) but also with CIRS-G $\geq 2$ for respiratory diseases (OR 14.98 [4-83$46.4], p<0.0001)$. There was no interaction between pulmonary HAI and CIRS-G Index ( $p$ LR test $=0.83$ ), between pulmonary HAI and CIRS-G for respiratory disease ( $p$ LR test $=0.90$ ), between main acute diagnosis and baseline ADL ( $\mathrm{p}$ LR test $=0.31$ ), and between pulmonary HAI and MMSE ( $p$ LR test $=0.71$ ). Because of co-linearity between overall (CIRS-G Index) and specific measures of severe comorbidities (CIRS-G $\geq 2$ for respiratory rho $0.34, p<0.0001$ or psychiatric diseases rho $0.22, p<0.005)$, we created two separate models, with the CIRS-G Index or with specific CIRS-G domains. MMSE, strongly associated with CIRS-G $\geq 2$ for psychiatric diseases (rho 0.41, $p<0.0001$ ), was not introduced in the model with specific domains.

Table 2 shows factors independently associated with functional decline during the rehabilitation unit stay. On multivariate analysis, functional decline was significantly associated with the CIRS-G Index and low MMSE values, with a non-significant association for low albumin level (Table 2, model 1). Adjustment for CRP was forced in models including albumin level, as CRP may be a confounder in the association between albumin level and functional decline. $P$-value of HosmerLemeshow test for model 1 was 0.49 indicating good calibration. Two CIRS-G-specific domains, namely respiratory and psychiatric diseases, and low albumin level were independently associated with functional decline (Table 2, model 2). Systematic adjustment for admission ADL value did not change the results (data not shown). After adjustment for CIRS-G index or specific respiratory or psychiatric CIRS-G, pulmonary HAI was not 
Table 1 Characteristics of older patients with or without functional decline during a rehabilitation unit stay and associated factors

\begin{tabular}{|c|c|c|c|c|c|}
\hline & & Functional & decline $^{a}$ dur & ing rehabilitation & unit stay \\
\hline & $\begin{array}{l}\text { Study } \\
\text { population } \\
n=160(\%)\end{array}$ & $\begin{array}{l}\text { Yes } \\
n=28(\%)\end{array}$ & $\begin{array}{l}\text { No } \\
n=132 \\
(\%)\end{array}$ & $\begin{array}{l}\text { Crude OR } \\
{[95 \% \mathrm{Cl}] \dagger}\end{array}$ & $P$ value $\neq$ \\
\hline Baseline characteristics & & & & & \\
\hline Age, years, median [Q1-Q3] & 84 [80-88] & $\begin{array}{l}83[81- \\
87.5]\end{array}$ & $84[80-88]$ & & 0.78 \\
\hline Male sex & $44(27.5)$ & $9(32.1)$ & $35(26.5)$ & & 0.55 \\
\hline Living alone & $110(68.8)$ & $19(67.9)$ & $91(68.9)$ & & 0.91 \\
\hline Place of residence & & & & & \\
\hline Home or assisted-living facility & $155(96.9)$ & $27(96.4)$ & $128(97.0)$ & & 0.88 \\
\hline Nursing home & $5(3.1)$ & $1(3.6)$ & $4(3.0)$ & & \\
\hline Main acute diagnosis & & & & & 0.48 \\
\hline Cardiovascular diseases & $36(22.5)$ & $6(21.4)$ & $30(22.7)$ & & \\
\hline Cerebrovascular diseases & $50(31.2)$ & $12(42.9)$ & $38(28.8)$ & & \\
\hline Orthopedic diseases (including fracture) & $35(21.9)$ & $4(14.3)$ & $31(23.5)$ & & \\
\hline Other diagnosis ${ }^{\mathrm{b}}$ & $39(24.4)$ & $6(21.4)$ & $33(25.0)$ & & \\
\hline ADL at admission in rehabilitation unit, median [Q1-Q3] & $7[4-10]$ & $5[3-10]$ & $7.5[4-10]$ & $0.91[0.81-1.03]$ & 0.14 \\
\hline Comorbidities & & & & & \\
\hline Global CIRS-G, median [Q1-Q3], OR/1-point increase $(n=164)$ & $11[8-13]$ & $\begin{array}{l}12.5[10- \\
15.5]\end{array}$ & $10[8-12]$ & $1.15[1.03-1.28]$ & 0.01 \\
\hline CIRS-G Index, median [Q1-Q3], OR/1-point increase & $4.0[3.5-5.5]$ & $6[4-6]$ & $4[3-5]$ & $1.46[1.14-1.86]$ & 0.003 \\
\hline Number of patients with CIRS-G score $\geq 2$ in each category, $r$ & & & & & \\
\hline Cardiovascular/respiratory system & & & & & \\
\hline Heart disease & $101(63.1)$ & $20(71.4)$ & $81(61.4)$ & & 0.32 \\
\hline Hypertension & $116(72.5)$ & $19(66.9)$ & $97(73.5)$ & & 0.55 \\
\hline Vascular/hematological diseases & $44(27.5)$ & $9(32.1)$ & $35(26.5)$ & & 0.55 \\
\hline Respiratory diseases & $34(21.3)$ & $11(39.3)$ & $23(17.4)$ & $3.07[1.27-7.41]$ & 0.01 \\
\hline Eye, ear, nose and larynx diseases & $36(22.5)$ & $6(21.4)$ & $30(22.7)$ & & 0.88 \\
\hline Gastrointestinal system & & & & & \\
\hline Upper gastrointestinal diseases & $12(7.5)$ & $3(10.7)$ & $9(6.8)$ & & 0.48 \\
\hline Lower gastrointestinal diseases & $13(8.1)$ & $3(10.7)$ & $10(7.6)$ & & 0.58 \\
\hline Hepatic diseases & $1(0.6)$ & $0(0)$ & $1(0.8)$ & & - \\
\hline Genitourinary system & & & & & \\
\hline Renal diseases & $56(35)$ & $14(50)$ & $42(31.8)$ & $2.14[0.94-4.90]$ & 0.07 \\
\hline Other urogenital diseases & $33(20.6)$ & $8(28.6)$ & $25(18.9)$ & $1.71[0.68-4.33]$ & 0.26 \\
\hline Musculoskeletal/intergumentary system & & & & & \\
\hline Muscle, bone, and skin diseases & $80(50.0)$ & $16(57.1)$ & $64(48.5)$ & & 0.41 \\
\hline Neuropsychiatric system & & & & & \\
\hline Neurological diseases & $42(26.3)$ & $10(35.7)$ & $32(24.2)$ & & 0.21 \\
\hline Psychiatric diseases & $120(75.0)$ & $25(89.3)$ & $95(72.0)$ & $3.25[0.92-11.40]$ & 0.06 \\
\hline General system & & & & & \\
\hline Endocrine and metabolic diseases & $44(27.5)$ & $10(35.7)$ & $34(25.8)$ & & 0.29 \\
\hline MMSE, median [Q1-Q3], OR/1-point decrease & $22[17-26]$ & 18 [15-25] & $23[18-27]$ & $1.10[1.02-1.18]$ & 0.02 \\
\hline MMSE $<24$ & $87(56.5)$ & $19(70.4)$ & $68(53.5)$ & $2.06[0.84-5.05]$ & 0.11 \\
\hline Albumin level $<35 \mathrm{~g} / \mathrm{L}$ & $86(53.5)$ & $21(75)$ & $65(49.2)$ & $3.09[1.23-7.77]$ & 0.02 \\
\hline
\end{tabular}


Table 1 Characteristics of older patients with or without functional decline during a rehabilitation unit stay and associated factors (Continued)

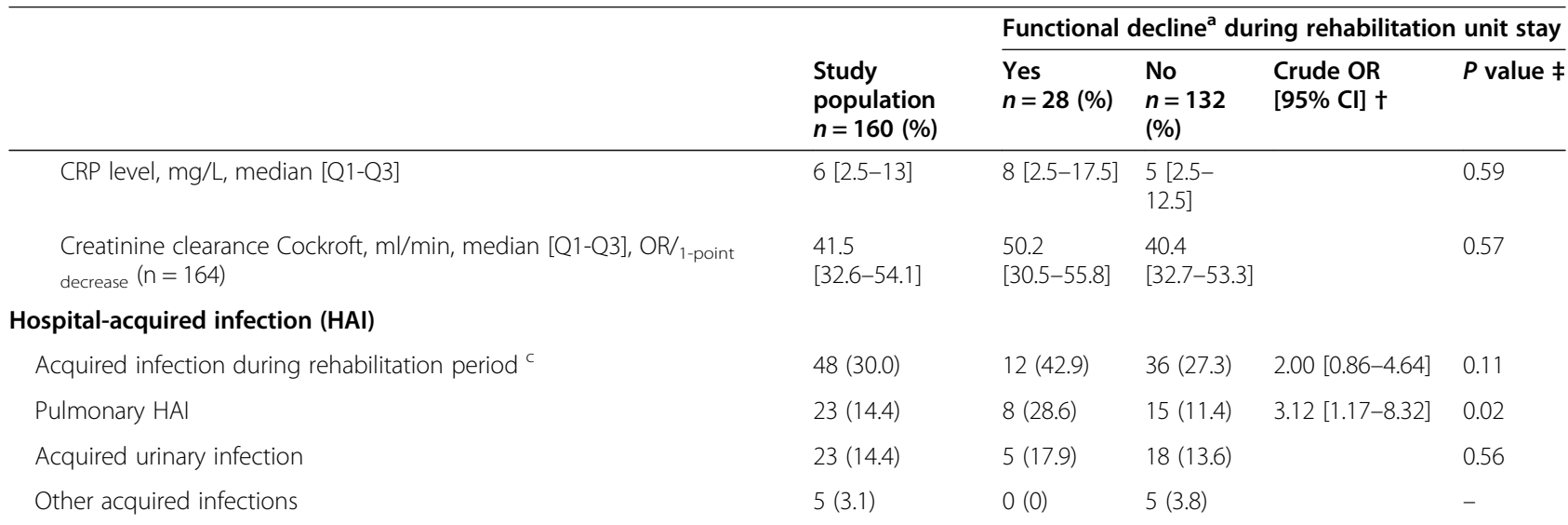

Abbreviation: OR Odds ratio, Cl Confidence interval, $A D L$ Activities of daily living, CIRS-G Cumulative Illness Rating Scale for Geriatrics, CRP C--reactive protein, MMSE Mini-Mental State Examination

The CIRS-G consists of 14 domains related to different body systems. Scoring on the different domains is weighted by the severity of the comorbid condition. Severity scores range from 0 (none) to 4 (extremely severe). The global score is the sum of each of the 14 domain scores. The CIRS-G index was calculated as the number of categories with score $\geq 2$

$(\mathrm{n}=)$ indicates the number of patients with available data

$\ddagger P$ value by logistic regression (Wald test)

${ }^{a}$ Functional decline was defined by at least a one-point decrease in ADL score during the rehabilitation unit stay

Including respiratory, gastrointestinal, and osteoarticular disease other than fracture

'Some patients had two or more acquired infections, so the sum of the patients in the three acquired infection groups is $>48$

significantly associated with functional decline. Therefore pulmonary HAI was not kept in final models. ADL score at baseline, CIRS-G $\geq 2$ for renal or other urogenital diseases were no longer significantly associated with functional decline after adjustment for CIRS-G index or CIRS-G for respiratory or psychiatric diseases and were not kept in final models. P-value of HosmerLemeshow test for model 2 was 0.39 indicating good calibration.

Significant or trend associations were observed $1 /$ between CIRS- $\mathrm{G} \geq 2$ for respiratory diseases and functional decline (crude OR 3.07 [1.27-7.41] 2/ between CIRS$\mathrm{G} \geq 2$ for respiratory diseases and pulmonary HAI (OR 14.98 [4-83-46.4] $p<0.0001$ ), and 3) between pulmonary HAI and functional decline (OR 3.12 [1.17-8.32]). The reduced effect of CIRS-G $\geq 2$ for respiratory diseases on functional decline observed after adjusting for pulmonary HAI (OR 2.26 [0.83-6.16] $p=0.11$ ) (Table 2) suggested partial potential mediation of acquired pulmonary HAI in the relation between CIRSG $\geq 2$ for respiratory diseases and functional decline.

\section{Sensitivity analyses}

The three sensivity analyses produced similar results (supplemental data - Appendix 2).

\section{Discussion}

Among patients 75 years and older referred to a geriatric rehabilitation unit from acute medical or surgical units, $17.5 \%$ had functional decline during their hospitalization

Table 2 Factors independently associated with deteriorated activities of daily living (ADL) during the rehabilitation unit stay

\begin{tabular}{lllll}
\hline & $\begin{array}{l}\text { Model 1 } \\
\text { Adjusted OR [95\%Cl] }\end{array}$ & P value & $\begin{array}{l}\text { Model 2 } \\
\text { Adjusted OR [95\%Cl] }\end{array}$ & $\begin{array}{c}\boldsymbol{P} \text { value } \\
\text { CIRS-G Index }\end{array}$ \\
CIRS-G score $\geq 2$ for respiratory diseases & $1.38[1.06-1.81]$ & 0.02 & - & - \\
CIRS-G score $\geq 2$ for psychiatric diseases & - & - & $3.23[1.21-8.59]$ & 0.02 \\
Albumin level $<35$ g/l & - & - & $4.89[1.27-18.72]$ & 0.02 \\
MMSE $_{\text {-point decrease }}$ & $2.65[0.98-7.10]$ & 0.05 & $2.98[1.12-7.92]$ & 0.03 \\
CRP & $1.09[1.00-1.18]$ & 0.03 & - & - \\
\hline
\end{tabular}

Adjusted ORs were estimated by logistic regression adjusted for CIRS-G index, Albumin level and MMSE for model 1 and adjusted for CIRS-G score $\geq 2$ for respiratory diseases, CIRS-G score $\geq 2$ for psychiatric diseases and Albumin level for model 2. (P value: Wald test)

MMSE Mini-Mental State Examination; CIRS-G Cumulative Illness Rating Scale for Geriatrics, CIRS-G Index calculated as the number of categories with score $\geq 2$. Model 1 considers factors associated with ADL deterioration and is adjusted by CIRS-G index, albumin level $<35 \mathrm{~g} / \mathrm{l}$, and MMSE. Model 2 considers factors associated with ADL deterioration and is adjusted for CIRS-G score $\geq 2$ for respiratory and psychiatric diseases and albumin level $<35 \mathrm{~g} / \mathrm{l}$. 
in the rehabilitation unit. Factors independently associated with functional decline were comorbidities assessed by the CIRS-G index and specifically the CIRS-G $\geq 2$ for respiratory or psychiatric diseases. This highlights the need of having a holistic and multiprofessional approach, centered on the person, to include all the dimension of the person from the assessment till the discharge, rather than a pure disciplinary-approach [34]. Our results also suggest that pulmonary HAI in patients hospitalized in rehabilitation units may mediate the relation between CIRS-G $\geq 2$ for respiratory diseases and functional decline.

To our knowledge, no previous study has estimated the incidence of acquired functional decline, assessed by $\mathrm{ADL}$, in older patients during a rehabilitation unit stay. In previous studies, functional improvement was assessed with different tools such as the Functional Independence Measure [22, 23, 25, 26, 29, 33] or the Barthel Index [27]. Comparing studies is difficult because of the heterogeneity of these tools. In keeping with two previous studies [33, 47], advanced age was not associated with functional decline.

In our study, comorbidities assessed by the CIRS-G, particularly severe psychiatric and respiratory diseases, were significant predictors of functional decline during the rehabilitation stay. One meta-analysis [26] showed that results concerning the association between functional decline and comorbidities are discordant. Tools used to assess comorbidities are heterogeneous. The main tools used are the Charlson comorbidity index, the comorbidity Index of Liu, the Comorbidity Severity Index or the CIRS-G. Only studies assessing comorbidities with indexes taking into account the severity of diseases such as the CIRS-G and not simple counts of comorbidities found an association between comorbidities and functional status [25, 28-31].

The proportion of HAI in our study was higher than one would expect in some geriatric rehabilitation. We can assume that in our study, physicians who collected data of HAI were more aware of diagnosis of HAI than other doctors because HAI was the main outcome of the cohort study [36]. One hypothesis could be the underreported of HAI in others studies as mentioned in one review [48]. The high proportion of patients with cerebrovascular diseases in our study could also explain this difference because patients with cerebrovascular diseases are more likely to have HAI especially pulmonary HAI [49]. Patients whose acute event was cerebrovascular disease seemed to experience more frequently functional decline than those whose acute event was orthopedic disease; this may reflect that cerebrovascular disease affects risk of functional decline and the potential link between HAI and functional decline.
Our findings are consistent with previous studies showing that cognitive impairment and depressive symptomatology predicted poor rehabilitation [7, 50, 51]. Similarly, in one cohort of 459 older patients hospitalized in a general medical service, risk of 1-month functional decline was two- to three-fold higher for patients with depression, delirium or with the overlap syndrome of depression and delirium than patients with neither depression nor delirium [52]. In our population, specific psychiatric CIRS -G concerned a major part of patients with cognitive dysfunction. The MMSE scores of the study population were lower than one would expect in a rehabilitation unit. Measure of cognitive function at rehabilitation admission could underestimate the true cognitive potential of patients.

The CIRS-G $\geq 2$ for respiratory diseases was associated with functional decline and with pulmonary HAI. Reduced ability to participate in physiotherapy cessions due to respiratory diseases may lead to peripheral muscle dysfunction and therefore functional decline [53]. An association between chronic respiratory diseases and pulmonary HAI was previously described in one Spanish study of a subacute care unit with frail older patients [32]. Inflammatory cytokine levels (tumor necrosis factor $\alpha$ ) are increased with pulmonary infection and were previously found to be associated with functional decline [54].

We found an association between low serum albumin level upon admission and functional decline persisting after adjustment for an inflammation marker (CRP level). Protein-calorie malnutrition, frequent in older people, leads to muscular loss and may explain this association [55].

Our study has certain strengths. Comorbidities were measured for all participants at baseline and were assessed by using a formal, validated and standard scale of comorbidity taking into account the severity of chronic diseases. This is the first study to analyze the association between functional decline and specific domains of the CIRS-G. This may be the first approach to explain the relation between functional decline and comorbidities, taking into account HAI.

However, the study contains several limitations. First, the single-center design of our study may have led to recruitment bias, thereby limiting external validity. Detailed operational characteristics, such as the intensity and frequency of physical therapy or other functional measure such as handgrip test, were not available for each patient [21]. Factors other than HAI occurring during the hospital stay could be involved in functional decline and we cannot exclude residual confounding factors in this cohort study. We did not analyze the impact of functional decline on future hospital readmission, quality of life, and social costs. Finally, from 
the initial cohort of 252 consecutive patients, only data for 160 were analyzed, which may have led to selection bias. However similar results obtained by sensitivity analyses support the robustness of our findings.

\section{Implications}

The goals of the rehabilitation unit for older patients are to achieve significant functional improvement mainly in mobility, thereby enabling these patients to return home in a relatively short time. However, we found that these tasks can be difficult to achieve in older patients with severe respiratory or cognitive impairment. We need to better identify patients at risk of functional decline before transfer to a rehabilitation unit. Having a HAI could influence relation between comorbidities and functional decline. We need to improve hygiene measures and the prevention of HAI in this population. It would be interesting to test in France the implementation of modern and individual programs of rehabilitation outside the hospital, such as those from Norway, Sweden and Spain [56-58] in particular for patients at-risk of HAI and hospital functional decline. Home-based occupational therapy, notably because occupational therapy has a personcentred approach focusing on the patient's own valued daily-activities, could improve functioning in frail older adults [59].

\section{Conclusion}

Among patients 75 years and older referred to a geriatric rehabilitation unit from acute medical or surgical units, incidence of functional decline during their hospitalization in rehabilitation unit was almost $20 \%$. Factors associated with functional decline were severe respiratory or cognitive impairment. Pulmonary Hospital-acquired infection in patients hospitalized in rehabilitation units may mediate the relation between respiratory diseases comorbidities and functional decline.

\section{Supplementary information}

Supplementary information accompanies this paper at https://doi.org/10. 1186/s12877-020-01813-3.

Additional file 1 : Appendix 1. Tableau A1. Characteristics of older patients with or without Activites of Daily Living (ADL) missing. Appendix 2. Tableau A2. Factors independently associated with ADL deterioration during rehabilitation unit stay, sensitivity analyses.

\section{Abbreviations \\ ADL: Activities of Daily Living; CIRS-G: Cumulative Illness Rating Scale for Geriatrics; CRP: C-reactive protein; EL: Evelyne Liuu; HAl: Hospital-Acquired Infection; ML: Marie Laurent; MMSE: Mini-Mental State Examination; IQR: InterQuartile Range; ORs: Odds Ratios}

\section{Acknowledgements}

We thank Laura Smales and Claudia Martínez-Tapia for language editing the manuscript.

\section{Authors' contributions}

ML, NO,JPD, FCP, LC,EL,EA,SBG, CE and EP made substantial contributions to the conception of the work. ML, EP and SBG also made contributions to design of the work; the acquisition, the analysis and interpretation of data and have drafted the work. NO analyzed and interpreted the patient data and have drafted the work. FCP and EA analyzed and interpreted the patient data. EL and LC and CE interpreted data and had substantively revised the article. ML and EL included patients. ML, NO, EP and SBJ were major contributors in writing the manuscript. All authors read and approved the final manuscript.

\section{Funding}

This study was supported by the Soins Courants 2006 grant SCR06010 from the French Ministry of Health, Direction de la Recherche Clinique. The funder had no role in study design, data collection, data analysis and interpretation, and in drafting the manuscript. Grant was used to finance Clinical Research Associate for data collection and statistician for data analysis support.

\section{Availability of data and materials}

The datasets used and/or analysed during the current study are available from the corresponding author on reasonable request. All data generated or analysed during this study are included in this published article [and its supplementary information files].

\section{Ethics approval and consent to participate}

This study was approved by an institutional review board (local Comitee Paris XII France) in compliance with the French legislation on observational studies (french law 20048006 aout 2004 bioéthique). Number SCR 06010 was attributed to this study. No ethical problem was found at the end of the evaluation by institutional review board. The study complied with the Declaration of Helsinki. All the study participants received written information about the use of their personal medical data for the study, and provided verbal consent. In compliance with the French legislation on observational studies, written informed consent was not required.

\section{Consent for publication}

Written informed consent was obtained from each patient before study inclusion. Written permission has been obtained from all persons named in the Acknowledgments. All ten authors have read and approved the manuscript, and none of the authors has any conflict of interest to report.

\section{Competing interests}

The authors declare no conflict of interest.

\section{Author details}

${ }^{1}$ Univ Paris Est Creteil, INSERM, IMRB, CEpiA Team, F-94010 Creteil, France. ${ }^{2} \mathrm{AP}-\mathrm{HP}$, Hopital Henri Mondor, Departement de médecine interne et gériatrie, F-94010 Creteil, France. ${ }^{3}$ Service de Santé Publique, AP-HP, Hôpital Henri Mondor, F- 94010 Creteil, France. ${ }^{4}$ Service de Gériatrie, AP-HP, Hôpital Emile Roux, F- 94450 Limeil Brévannes, France. ${ }^{5}$ Univ Paris Est Creteil, Occupational Therapy Institute (IFE), F -94010 Creteil, France. ${ }^{6} \mathrm{CHU}$ de Poitiers, Service de gériatrie, 2, rue de la Milétrie, F-86021 Poitiers, France. ${ }^{7}$ Service de Gériatrie, AP-HP, Hôpital Europeen Georges Pompidou, F-75015 Paris, France.

Received: 23 March 2020 Accepted: 30 September 2020

Published online: 29 October 2020

References

1. Gill TM, Allore HG, Holford TR, Guo Z. Hospitalization, restricted activity, and the development of disability among older persons. JAMA. 2004;292(17): 2115-24.

2. Fortinsky RH, Covinsky KE, Palmer RM, Landefeld CS. Effects of functional status changes before and during hospitalization on nursing home admission of older adults. J Gerontol A Biol Sci Med Sci. 1999;54(10):M5216.

3. Campbell SE, Seymour DG, Primrose WR, Project A. A systematic literature review of factors affecting outcome in older medical patients admitted to hospital. Age Ageing. 2004;33(2):110-5.

4. Dagani J, Ferrari C, Boero ME, Geroldi C, Giobbio GM, Maggi P, et al. A prospective, multidimensional follow-up study of a geriatric hospitalised 
population: predictors of discharge and well-being. Aging Clin Exp Res. 2013;25(6):691-701.

5. Volpato S, Onder G, Cavalieri M, Guerra G, Sioulis F, Maraldi C, et al. Characteristics of nondisabled older patients developing new disability associated with medical illnesses and hospitalization. J Gen Intern Med. 2007;22(5):668-74.

6. Sager MA, Rudberg MA, Jalaluddin M, Franke T, Inouye SK, Landefeld CS, et al. Hospital admission risk profile (HARP): identifying older patients at risk for functional decline following acute medical illness and hospitalization. J Am Geriatr Soc. 1996;44(3):251-7.

7. Pedone C, Ercolani S, Catani M, Maggio D, Ruggiero C, Quartesan R, et al. Elderly patients with cognitive impairment have a high risk for functional decline during hospitalization: the GIFA study. J Gerontol A Biol Sci Med Sci. 2005;60(12):1576-80

8. McCusker J, Kakuma R, Abrahamowicz M. Predictors of functional decline in hospitalized elderly patients: a systematic review. J Gerontol A Biol Sci Med Sci. 2002;57(9):M569-77.

9. Lang PO, Meyer N, Heitz D, Drame M, Jovenin N, Ankri J, et al. Loss of independence in Katz's ADL ability in connection with an acute hospitalization: early clinical markers in French older people. Eur J Epidemiol. 2007;22(9):621-30.

10. Gagliardi C, Corsonello A, Di Rosa M, Fabbietti P, Cherubini A, Mercante O, et al. Pre-admission functional decline predicts functional improvement among older patients admitted to acute care hospital. J Gerontol A Biol Sci Med Sci. 2017; http://www.ncbi.nlm.nih.gov/pubmed/29087448.

11. Fimognari FL, Pierantozzi A, De Alfieri W, Salani B, Zuccaro SM, Arone A, et al. The severity of acute illness and functional trajectories in hospitalized older medical patients. J Gerontol A Biol Sci Med Sci. 2017;72(1):102-8.

12. Zisberg A, Shadmi E, Gur-Yaish N, Tonkikh O, Sinoff G. Hospital-associated functional decline: the role of hospitalization processes beyond individual risk factors. J Am Geriatr Soc. 2015;63(1):55-62.

13. Johannesen APJ, Avlund K. Satisfaction in everyday life for frail 85-year-old adults: a Danish population study. Scan J Occup Ther. 2004;11(1):3-11.

14. Foley R-A AC, Anchisi A, Anchisi S. Apports d'une approche interdisciplinaire. Bulletin des Médecins Suisses. 2015;96(4):94-7.

15. Hartigan I. A comparative review of the Katz ADL and the Barthel index in assessing the activities of daily living of older people. Int J Older People Nursing. 2007;2(3):204-12.

16. Shelkey M, Wallace M, Nursing HIfG. Try this: best practices in nursing care to older adults. Katz Index of Independence in Activities of Daily Living (ADL). MEDSURG Nurs. 2002;11(2):2.

17. Buntin MB. Access to postacute rehabilitation. Arch Phys Med Rehabil. 2007; 88(11):1488-93.

18. Neouze A, Dechartres A, Legrain S, Raynaud-Simon A, Gaubert-Dahan ML, Bonnet-Zamponi D. Hospitalization of elderly in an acute-care geriatric department. Geriatr Psychol Neuropsychiatr Vieil. 2012;10(2):143-50 http:// www.ncbinlm.nih.gov/pubmed/22713842.

19. De Saint-Hubert M, Schoevaerdts D, Cornette P, D'Hoore W, Boland B, Swine C. Predicting functional adverse outcomes in hospitalized older patients: a systematic review of screening tools. J Nutr Health Aging. 2010;14(5):394-9.

20. van Dam van Isselt EF, Spruit M, Groenewegen-Sipkema KH, Chavannes NH, Achterberg WP. Geriatric rehabilitation for patients with advanced chronic obstructive pulmonary disease: a naturalistic prospective cohort study on feasibility and course of health status. Chron Respir Dis. 2014;11(2):111-9.

21. Bachmann S, Finger C, Huss A, Egger M, Stuck AE, Clough-Gorr KM. Inpatient rehabilitation specifically designed for geriatric patients: systematic review and meta-analysis of randomised controlled trials. BMJ. 2010;340:c1718.

22. Rolland Y, Pillard F, Lauwers-Cances V, Busquere F, Vellas B, Lafont C Rehabilitation outcome of elderly patients with hip fracture and cognitive impairment. Disabil Rehabil. 2004;26(7):425-31.

23. Hershkovitz A, Kalandariov Z, Hermush V, Weiss R, Brill S. Factors affecting short-term rehabilitation outcomes of disabled elderly patients with proximal hip fracture. Arch Phys Med Rehabil. 2007;88(7):916-21.

24. Uriz-Otano F, Pla-Vidal J, Tiberio-Lopez G, Malafarina V. Factors associated to institutionalization and mortality over three years, in elderly people with a hip fracture-an observational study. Maturitas. 2016;89:9-15.

25. Press Y, Grinshpun Y, Berzak A, Friger M, Clarfield AM. The effect of comorbidity on the rehabilitation process in elderly patients after hip fracture. Arch Gerontol Geriatr. 2007;45(3):281-94.

26. Kabboord AD, van Eijk M, Fiocco $M$, van Balen $R$, Achterberg WP. Assessment of Comorbidity Burden and its Association With Functional
Rehabilitation Outcome After Stroke or Hip Fracture: A Systematic Review and Meta-Analysis. J Am Med Dir Assoc. 2016;17(11):1066.e13-21 http:// www.ncbi.nlm.nih.gov/pubmed/27663529.

27. Koot VC, Peeters PH, de Jong JR, Clevers GJ, van der Werken C. Functional results after treatment of hip fracture: a multicentre, prospective study in 215 patients. Eur J Surg. 2000;166(6):480-5.

28. Patrick L, Knoefel F, Gaskowski P, Rexroth D. Medical comorbidity and rehabilitation efficiency in geriatric inpatients. J Am Geriatr Soc. 2001;49(11):1471-7.

29. Di Libero F, Fargnoli M, Pittiglio S, Mascio M, Giaquinto S. Comorbidity and rehabilitation. Arch Gerontol Geriatr. 2001;32(1):15-22.

30. Giaquinto S, Palma E, Maiolo I, Piro MT, Roncacci S, Sciarra A, et al. Importance and evaluation of comorbidity in rehabilitation. Disabil Rehabil. 2001;23(7):296-9.

31. Rozzini R, Frisoni GB, Ferrucci L, Barbisoni P, Sabatini T, Ranieri P, et al. Geriatric index of comorbidity: validation and comparison with other measures of comorbidity. Age Ageing. 2002;31(4):277-85.

32. Ticinesi A, Nouvenne A, Folesani G, Prati B, Morelli I, Guida L, et al. An investigation of multimorbidity measures as risk factors for pneumonia in elderly frail patients admitted to hospital. Eur J Intern Med. 2016;28:102-6.

33. Landi F, Bernabei R, Russo A, Zuccala G, Onder G, Carosella L, et al. Predictors of rehabilitation outcomes in frail patients treated in a geriatric hospital. J Am Geriatr Soc. 2002;50(4):679-84.

34. Covinsky KE, Pierluissi E, Johnston CB. Hospitalization-associated disability: "she was probably able to ambulate, but I'm not sure". JAMA. 2011;306(16): 1782-93.

35. Eriksen HM, Iversen BG, Aavitsland P. Prevalence of nosocomial infections and use of antibiotics in long-term care facilities in Norway, 2002 and 2003. J Hosp Infect. 2004:57(4):316-20.

36. Laurent M, Bories PN, Le Thuaut A, Liuu E, Ledudal K, Bastuji-Garin S, et al. Impact of comorbidities on hospital-acquired infections in a geriatric rehabilitation unit: prospective study of 252 patients. J Am Med Dir Assoc. 2012;13(8):760.e7-12 http://www.ncbi.nlm.nih.gov/pubmed/22885408.

37. Miller MD, Paradis CF, Houck PR, Mazumdar S, Stack JA, Rifai AH, et al. Rating chronic medical illness burden in geropsychiatric practice and research: application of the cumulative illness rating scale. Psychiatry Res. 1992;41(3):237-48.

38. Folstein MF, Folstein SE, McHugh PR. "mini-mental state". A practical method for grading the cognitive state of patients for the clinician. J Psychiatr Res. 1975;12(3):189-98.

39. santé Had. Diagnostic de l'insuffisance rénale chronique chez l'adulte. Synthèse des recommandations. 2002.

40. Raynaud-Simon A, Revel-Delhom C, Hebuterne X, French N, Health Program FHHA. Clinical practice guidelines from the French Health high authority: nutritional support strategy in protein-energy malnutrition in the elderly. Clin Nutr. 2011;30(3):312-9.

41. Garner JS, Jarvis WR, Emori TG, Horan TC, Hughes JM. CDC definitions for nosocomial infections, 1988. Am J Infect Control. 1988;16(3):128-40.

42. Katz $\mathrm{S}$, Ford $A B$, Moskowitz RW, Jackson BA, Jaffe MW. Studies of illness in the aged. The index of Adl: A standardized measure of biological and psychosocial function. JAMA. 1963;185:914-9.

43. Baron RM, Kenny DA. The moderator-mediator variable distinction in social psychological research: conceptual, strategic, and statistical considerations. J Pers Soc Psychol. 1986;51 (6):1173-82.

44. Lockwood CM, Defrancesco CA, Elliot DL, Beresford SA, Toobert DJ. Mediation analyses: applications in nutrition research and reading the literature. J Am Diet Assoc. 2010;110(5):753-62.

45. Richiardi L, Bellocco R, Zugna D. Mediation analysis in epidemiology: methods, interpretation and bias. Int J Epidemiol. 2013;42(5):1511-9.

46. Audureau E, Pouchot J, Coste J. Gender-related differential effects of obesity on Health-related quality of life via obesity-related comorbidities: A mediation analysis of a French Nationwide survey. Circ Cardiovasc Qual Outcomes. 2016;9(3):246-56.

47. Singh I, Gallacher J, Davis K, Johansen A, Eeles E, Hubbard RE. Predictors of adverse outcomes on an acute geriatric rehabilitation ward. Age Ageing. 2012:41(2):242-6.

48. Curtis LT. Prevention of hospital-acquired infections: review of nonpharmacological interventions. J Hosp Infect. 2008;69(3):204-19.

49. Hannawi Y, Hannawi B, Rao CP, Suarez Jl, Bershad EM. Stroke-associated pneumonia: major advances and obstacles. Cerebrovasc Dis. 2013;35(5):430-43.

50. Gialanella B, Ferlucci C, Monguzzi V, Prometti P. Determinants of functional outcome in hip fracture patients: the role of specific neuropsychiatric symptoms. Disabil Rehabil. 2015;37(6):517-22. 
51. McGilton KS, Chu CH, Naglie G, van Wyk PM, Stewart S, Davis AM. Factors influencing outcomes of older adults after undergoing rehabilitation for hip fracture. J Am Geriatr Soc. 2016;64(8):1601-9.

52. Givens JL, Jones RN, Inouye SK. The overlap syndrome of depression and delirium in older hospitalized patients. J Am Geriatr Soc. 2009;57(8):1347-53.

53. Fried TR, Vaz Fragoso CA, Rabow MW. Caring for the older person with chronic obstructive pulmonary disease. JAMA. 2012;308(12):1254-63.

54. El Solh A, Pineda L, Bouquin P, Mankowski C. Determinants of short and long term functional recovery after hospitalization for community-acquired pneumonia in the elderly: role of inflammatory markers. BMC Geriatr. 2006;6: 12.

55. Bonnefoy M, Berrut G, Lesourd B, Ferry M, Gilbert T, Guerin O, et al. Frailty and nutrition: searching for evidence. J Nutr Health Aging. 2015;19(3):250-7.

56. Langeland E, Tuntland H, Forland O, Aas E, Folkestad B, Jacobsen FF, et al. Study protocol for a multicenter investigation of reablement in Norway. BMC Geriatr. 2015;15:111.

57. Closa C, Mas MA, Santaeugenia SJ, Inzitari M, Ribera A, Gallofre M. Hospitalat-home integrated care Program for older patients with orthopedic processes: an efficient alternative to usual hospital-based care. J Am Med Dir Assoc. 2017;18(9):780-4.

58. Berggren M, Karlsson A, Lindelof N, Englund U, Olofsson B, Nordstrom P, et al. Effects of geriatric interdisciplinary home rehabilitation on complications and readmissions after hip fracture: a randomized controlled trial. Clin Rehabil. 2018. https://doi.org/10.1177/0269215518791003.

59. De Coninck L, Bekkering GE, Bouckaert L, Declercq A, Graff MIL, Aertgeerts B. Home- and community-based occupational therapy improves functioning in frail older people: A systematic review. J Am Geriatr Soc. 2017:65(8):1863-9.

\section{Publisher's Note}

Springer Nature remains neutral with regard to jurisdictional claims in published maps and institutional affiliations.

Ready to submit your research? Choose BMC and benefit from:

- fast, convenient online submission

- thorough peer review by experienced researchers in your field

- rapid publication on acceptance

- support for research data, including large and complex data types

- gold Open Access which fosters wider collaboration and increased citations

- maximum visibility for your research: over $100 \mathrm{M}$ website views per year

At $\mathrm{BMC}$, research is always in progress.

Learn more biomedcentral.com/submissions 